\title{
A Wage-Increase Permit Plan to Stop Inflation
}

I WANT TO DISCUSS not the sons of TIP but what is perhaps a grandson toward which the TIP family is developing. It is a wage-increase permit plan (WIPP), about which I have written briefly in Challenge and Social Research. ${ }^{1}$ Although I consider WIPP more logical, manageable, and effective than any of the TIPs, I said in those articles that I would support some form of TIP that seemed more likely to be acceptable and implemented. But the discussion at this conference has convinced me that the objections to the various TIPs are much more serious than I had supposed, that most of them would not apply to WIPP, and that it is not at all clear that a TIP would indeed be more likely to be accepted. I have also been thinking more about WIPP, developing it further, and becoming more fond of it, so I want to restate it.

WIPP is based on a view of the economy such as that suggested by Perry. In my view, inflation in the United States is not caused by excess demand, but by self-fulfilling expectations, with prices rising at about 6 percent to keep up with the cost of production, compensation rising at about 9 percent to keep up with the cost of living and increasing productivity, while the government keeps increasing total spending in the economy to prevent catastrophic unemployment. There is a vicious circle of rising prices, rising wages, and rising total spending in which none of these can stop because the others are going on. And yet there is a new kind of fairly stable, process equilibrium - a 6 percent expectational inflation.

1. "Stagflation-Its Cause and Cure," Challenge, vol. 20 (September/October 1977), py. 14-19; and "From Pre-Keynes to Post-Keynes," Social Research, vol. 47 (Fall 1977).

$00072,303 / 78 / 0002-0491 / \$ 00.25 / 0$ (1) Brookings Institution 
This condition of the economy is the result of a flaw in the market mechanism. Important lessons are to be learned from the natural history of another flaw. During World War II there arose a "shortage" of some essential items that led to intolerable price increases. The poor were deprived of vital necessities that the rich were using wastefully.

The natural history begins with price control. That leads to black markets and to arbitrary and discriminatory informal rationing by shopkeepers. The informal rationing is then replaced by official formal rationing. This is still considered bothersome and wasteful and is greatly improved by point rationing, under which the same ration points can be used for several substitutes. Next there are ration points that are valid for wider ranges of goods and reduce illegal trading of rations and ration tickets. The final stage would take the form of Michal Kalecki's general rationing. This rationing uses a single set of points expressed in money, which essentially serves only as permits to limit the amount of money any individual can spend on the "scarce" essential commodities.

As the scarcity abated after the war, the prices of the scarce items fell so low that the allotted permits (which had drawn large black market prices) almost made possible the purchase of more than people wanted to buy. These permits would have become redundant and quite worthless, but the entire system was scrapped before this happened, which provided a more dramatic (if somewhat synthetic) occasion for celebrating decontrol.

TIP is a similar development of procedures (although not completed) for correcting a flaw in the market mechanism, and most of the objections to TIP raised at this conference owe their validity only to the incompleteness of the correction of the flaw. The flaw in the present instance is a mutation of the flaw responsible for the great depression of the 1930s.

That flaw was diagnosed by Keynes and its cure prescribed in 1936 in the more elementary chapters of The General Theory of Employment, Interest and Money. It was the failure of wages to fall far enough and fast enough in response to a deficiency in demand for labor to maintain a satisfactory level of output and employment, given the level of total spending. The cure was easy because of the availability of a free variable-increases in the level of spending. This could be adjusted to take the place of the decrease in wages and prices that was missing. It was costless because of the great scope for continuing government deficits and the growth of intra- 
national debt, and the unlimited scope for costless increases in the quantity of money.

The mutation is that wages do not merely refuse to fall but keep rising, caught in a self-fulfilling expectational inflation. Government and businesses, which seem to have an incurable propensity to treat inflation as if it were due to too much total spending, hold down their spending as long as prices are rising, but desist from this when the resulting unemployment threatens to reach double digits. This is what creates stagflation but does not lead to catastrophic depression.

The simple Keynesian remedy is not effective in dealing with this mutation. The task is now twofold: it is necessary to stabilize the average price (the price level), with average wages rising at the national average rate of productivity increase; and to adjust relative wages and relative prices to the continuing changes in tastes and techniques. To accomplish this task the vicious circle of rising wages, prices, and total spending must be broken. Stopping any one of them could break the spell in which each has to keep rising because the others are rising. But stopping the spending, which the government could bring about, only works through catastrophic depression and severe unemployment. Alternatively, prices or wages could be stabilized. Prices, however, are much more complicated than wages, and price regulation is more easily evaded by quality changes. The best option seems to be to stabilize wages, which are already largely administered by collective bargaining and other large-scale wage decisions.

In the 1940s I developed some rules for wage regulation to achieve the twofold objective and published them in my Economics of Employment in 1951. Later this was attempted in practice by wage-price guidelines and guideposts, which included price regulation for political purposes. The first objective was achieved with some success by a freeze of prices and wages, but it was soon eroded by the regulations for adjusting relative wages and prices.

These regulations became an administrative nightmare parallel to the use of price controls against the intolerable price increases caused by scarcities in World War II. The administrators were unable to handle the complexities or deal with the resistances. The bureaucratic, administrative decision mechanism broke down. The task required local decisions by local people who knew the local conditions; thus, something more like a decentralized market mechanism was needed. 


\section{Tax-Based Incomes Policy}

A great step forward was made by Weintraub and Wallich in proposing such a device in their tax-based incomes policy (TIP). Weintraub used the analogy to laws against speeding, laws that people can break if they are prepared to pay the fine. The analogy is faulty because a speeding law that succeeded in keeping everyone below the speed limit would be regarded as successful. What is needed is a rule-if you could call it that -which would normally and properly be broken half the time.

To fulfill the twofold task of keeping the average price constant while leaving individual prices free, average wages must continue rising at a norm equal to the national average rate of productivity increase while leaving individual wage rates free. For this it is necessary to discourage the granting of wage increases (or to provide an incentive to resist wage increases) in a way that will still permit some wage increases to exceed the norm by as much as other wage increases fail to reach the norm.

If TIP were adjusted to eliminate all subsidies and to provide equal tax incentives at all levels for equal reductions in the amounts of wage increase, with no lower or upper limit (no minimum threshold and no maximum of any kind), it would solve the incentive problem efficiently. ${ }^{2}$ (These are indeed the adjustments I suggested in proposing to support TIP rather than WIPP in my Challenge article; the second condition, equal tax incentives, is similar to adjustments suggested by Seidman.) But TIP would still be left with much of the "litigation nightmare" of unlimited disputes about the appropriateness or the equity of the charges and the subsidies in different situations, because it does not solve the problem of deciding how strong to make the tax incentive. It would correct only part of the flaw.

TIP would mobilize the essential function of price in the market

2. Subsidies are proposed only because of a confusion between the necessity of offsetting the effects of taxes on total spending and the desirability of ameliorating hardships. Hardships apply to people, rather than businesses, and their amelioration calls for income benefits, not changes in prices or wages. Similarly, the word "penalty" is unfortunate because it suggests a punishment imposed for wrongdoing. TIP would impose something like a price, which, as always, discourages people from buying something because they would rather keep the money for other purposes. It is not a punishment for any improprieties. This does not rule out the grants or tax reductions required to increase total demand in order to offset the effect of the incentive tax in reducing total demand. 
mechanism, which is to discourage whatever activity calls for a price to be paid and, its mirror image, to encourage whatever enables a price to be received. Still missing would be the other hali of the market mechanism, the guide to free decisions in the social interest by the establishment of price at the level that equates supply and demand. WIPP, unlike TIP, uses the market mechanism to provide this guide and to adjust the incentive to the strength required.

\section{Wage-Increase Permit Plan}

WIPP works as follows:

(1) The government would grant "wage increase permits" to every employer who qualified by employing more than, say, 100 workers or any workers whose wages were fixed by an agreement that covered more than 100 workers-for instance, one permit for each $\$ 1,000$ of the employer's total costs of employment (called his "wage bill," but including all fringe benefits and so forth). ${ }^{3}$ Records would be kept of the employer's wage bill from a base date, including each employee's wages (pay plus the employee's share of the other costs of employment) ${ }^{4}$

(2) Newly hired employees, including all employees of new firms, would enable their qualified employers to obtain additional permits and also a permit for each $\$ 1,000$ of the new employee's wages. Conversely, on the separation of an employee from a firm, including all the employees of a firm that closes, the corresponding number of permits would have to be returned to the permit authority. This would adjust the total number of permits to changes in the wage bill that were due to changes in employment, rather than to changes in the wage level. ${ }^{5}$

3. "It is now uniformly recognized that payments to common benefit trust funds providing pension welfare, vacation and vocation training and other benefits represent a substantial economic portion of employee wages . . .." (Statements and Reports Adopted by the AFL-CIO Executive Council, Bal Harbour, Florida, February 20-27, 1978, pp. 57-58).

4. Some components of these data are required by the Internal Revenue Service or by the Social Security Administration, with which the permit authority would cooperate. The firm could allocate its total fringe benefits among the employees in any way it chose as long as the total cost of all the fringe benefits was included in the wage bill.

5. Care would have to be taken to prevent evasion by firing and rehiring at higher pay (to obtain free permits for an "employment increase" instead of buying permits for what is really a wage increase) and to avoid related collusions between firms and unions or among firms to exchange employees for this purpose. 
(3) Each permit would give the employer who held it the right (by raising wage rates) to raise his adjusted wage bill by, say, $\$ 30$ per permit ( 3 percent of the face value of his permits, which is the estimated national average rate of increase in output per employee-_"productivity").

(4) The permits would be freely tradable in a perfectly competitive market, like a share of IBM in the stock exchange. Any employer who wished to increase his adjusted wage bill by more than 3 percent by raising wage rates would have to acquire more permits. He could obtain them only through purchase from others who had to reduce the increase in their wage bill by the same amount below 3 percent. Any employer who reduced his wage bill would qualify for a grant of additional permits for the corresponding amount (one permit for each $\$ 30$ cut from a wage bill), and could sell those permits. The national total wage bill would thereby always be raised just 3 percent a year by the wage bill increases of the different firms. Because the wage bill is adjusted for changes in employment at the level of the firm and at the national level, the national average wage would continue to rise at 3 percent a year. The price of the permit would be set by the market at the level at which supply equals demand; this price would just offset inflationary expectations for raising wages more than productivity.

A year later each 100 old permits would be replaced by 103 new, dated, $\$ 1,000$ permits. The total number of permits at the national level would therefore keep up with both components of the national total wage bill: the volume of employment and the national average wage.

WIPP would thus indeed "whip inflation now" by achieving the essential twofold objective. It would keep the average wage rising at the same rate as output per worker, eliminating price-level inflation, and leave each particular wage free for determination by individual or collective bargaining. All other prices would be left for free market determination established before WIPP was introduced. The money paid or received for permits would then be just one more of the many considerations that influence wage settlements.

\section{A Comparison of the Two Proposed Policies}

Wage bargaining - both individual and collective-could proceed as it did before the adoption of an anti-inflation policy, and the same would be true for setting prices by the market. WIPP, like TIP, does not address 
other market imperfections, such as restrictive practices, monopoly, monopsony, cartels, and oligopolies. It does not prevent monopsonistic exploitation of workers in company towns or keep strong unions from forcing employers to grant exorbitant wage increases. And it does not stop unions from persuading the government to put pressure on employers when a strike threatens to endanger the economy or the health or safety of the public. For the purposes of WIPP, no individual wage, firm wage average, or wage increase is too much or too little. WIPP is concerned with only the national average rate of wage increase.

One important difference between WIPP and TIP is that the former induces employers to buy the required permits from other employers. The gains from such inducement are then clearly seen to be made at the expense of other workers whose employers sell these same permits.

This is the elementary lesson that the economics profession has failed to teach effectively. WIPP permits could prevent the pressure groups from recruiting the support of the victims of their extortion. The other workers whose wage increase permits are taken away would be reluctant to support the extortion under the fraudulent slogans of working class solidarity or to honor the picket lines that are picking their own pockets.

TIP, as modified, would simulate price by using the tax as a uniform incentive for resisting the pressure for wage increases, but it would provide no guideline to indicate how large the tax must be to offset this pressure or to monitor the changes in the pressure.

This pressure is nothing but the impact of inflationary expectations. At present these seem to be about 9 percent for average compensation and 6 percent for average prices. If either TIP or WIPP were adopted, these expectations and the consequent pressures would decrease, and the incentives would have to be reduced. Legislative and administrative adjustment of the taxes are much too slow; they would work like decisions required to change the price of IBM in the stock exchange.

In speaking of WIPP as "internalizing the inflation externality," as I sometimes have, I was shortchanging it. The adjusted TIP also internalizes it, but the legislative nightmare, which is diminished by making the TIP tax uniform, can be removed only by WIPP's correction of the flaw in the market mechanism.

"Internalization" is borrowed from pollution theory, where pollution permits are an improvement on earlier antipollution cries such as "prohibit it" or "limit it." But modern economists, prodded by Ronald Coase, 
understand that the government would be justified in fixing a price for a permit to pollute only if a proper market could not be established.

But if a market were established (which would require definition of a previously undefined, or inadequately defined property right and the settlement of clear ownership), there would no longer be a "pollution problem." There would be merely one more scarce commodity on the market. The externality has not merely been internalized by a charge, tax, or permit and converted into a cost at a level decided by an administrative or a legislative authority. Something more has been done. The externality has been made to reflect the value of the damage as indicated on the market by the damaged party. The market mechanism now serves as a guide to the proper intensity of the incentive. No litigation is required. The market determines the correct price. Clarification of property rights is the euthanasia of litigation.

This completion of the correction of the flaw corresponds to Kalecki's general rationing, which prevents the rich from wasting the necessities of the poor; it completes the process of reestablishing the market by making the general ration points legally tradable.

WIPP thus automatically adjusts the price of a wage-increase permit to the level of the current self-fulfilling inflationary expectations. As it offsets the expectation of inflation, it diminishes the inflationary wage increase, the cost increase, and the price increase. This lowering in actual inflation reduces expectation of further inflation and thereby further decreases actual inflationary wages, costs, and prices. The inflation is automatically deflated. The self-fulfilling expectational inflation becomes selfliquidating.

Because the power of WIPP lies in the price of the permit, and that price is equated in the market to the pressure of the inflationary expectations, and because the inflationary expectations rest on the experience of actual inflation, the price of the permit and the power of WIPP decrease in parallel with the inflation. In making the inflation self-liquidating, WIPP also makes itself automatically self-liquidating.

The decline of the WIPP permit price to zero when the inflationary pressure, the inflation, and WIPP itself are all liquidated corresponds to the eroding of the scarcity and the consequent disappearance of the general rationing permits.

My support of TIP rather than WIPP was partly due to the belief that WIPP would seem to too many people like a wild-eyed revolutionary 
dream too good to be true. But it is indeed a most conservative device that is operating in our economy countless times each day. It leaves each of the large number of quantities of some item unregulated-for free determination by a large number of people concerned with it-while the average of all these quantities remains fixed. What makes WIPP seem strange is only that the item is a new one and has not been treated in this familiar way in the past.

One example of the familiar miracle will suffice. The number of oranges per consumer is freely chosen by him when he takes the equilibrium price into consideration. This price, reached by the market, automatically makes the average number of oranges demanded per consumer just equal to the average number available per consumer because the total number demanded is equal to the total number supplied.

For this miracle to work, society had to decide to make the ownership of oranges a legal property right of individuals. This undoubtedly was an impious, revolutionary, and antisocial idea when first suggested to the head of a tribe where individual rights were nonexistent.

The new property right that needs to be created unfortunately is quite different from an orange. It is the right of an employer to raise his wage bill and thus his average wage. The property right comes in units of $\$ 30$; its ownership is registered by the possession of one $\$ 1,000$ permit. Its (uniform) price and its annual rental are determined by supply and demand in the market in which the permits (rights) are freely exchanged by buyers and sellers and borrowers and lenders. This system of rights could correct the flaw in the market mechanism that has resulted in the present inflation.

\section{Recent Questions Raised}

I conclude by touching briefly on a number of questions about WIPP and TIP that have been raised here and elsewhere.

(1) The relatively stable price inflation of 6 percent a year that has been experienced in the last few years has as much right to be called an equilibrium state as the Keynesian unemployment equilibrium of stable wages. This may seem strange to those who have learned from the textbook that a rise in price occurs only when there is excess demand-when demand exceeds supply and there is no equilibrium. But that rule relies 
on a hidden, perhaps unnoticed, assumption that stable prices had been expected. It is only a special case of a more general rule. The more general rule says that, if there is excess demand, the previous expectation is raised and the price will rise faster than had been expected. In the special case in which the expectation of increased price is zero, excess demand would cause price to rise faster than zero, and the words "faster than zero" are taken as understood. After all, rising seems to mean rising faster than zero.

If, however, the expectation was not a zero rise in price but a 6 percent price increase, an excess demand, which always makes prices rise more than expected, would now bring about a price rise of more than 6 percent. When demand equals supply, with no disappointed buyers or sellers, no change would occur, but again there would be no change in the expectation-that is, a confirmation of previous expectations and a continuing of the equilibrium 6 percent rate of price inflation. This equilibrium is the vicious circle that TIP and WIPP have to break.

(2) WIPP and TIP share the strategy of placing a price on the granting of wage increases (over and above the actual wage increases) that would make inflationary wage increases more expensive. The use of expressions like "penalty" instead of price or charge is responsible for proposals of progressive punishment for more heinous "crimes" in the form of more than proportional charges for larger wage increases. But price functions properly only if the total paid is proportional to the amount bought, and this also applies to the price paid for granting wage increases.

(3) More recent estimates have reduced the rate of increase in output per worker from 3 to 2 percent. I think this is partly a reflection of the state of depression in our stagflation in which output declines in a larger proportion than employment, so that the figure would return to the previous 3 percent or so if TIP or WIPP succeeded in conquering the stagflation. The reduction may also occur because more resources are used to produce benefits that do not appear in the measure of output-such as improvement of the environment for which only the costs are shown in the figures for output per worker.

However, it will not make much difference whether the figure adopted is 3 percent, 2 percent, or 4 percent. Any one of these will yield a stable rate of inflation between +1 percent and -1 percent and none of the serious inflation or stagflation problems.

There have also been suggestions that instead of setting the wage in- 
crease norm at the final goal of 3 percent (or 2 percent or 4 percent), it should be gradually lowered from the current 9 percent to reach the final figure only after a number of years. One reason given for this is that a sudden end to the inflation would give an unfair advantage to those whose compensation had recently been raised at the inflationary rate of about 9 percent, compared to those who had been waiting a year or two for their raise when the imposition of TIP or WIPP reduced theirs to about 3 percent. But other devices are available for correcting such inequities. To soften this effect is much too expensive. It would cost only a tiny fraction of this to provide even the most generous compensation to those who may have been harmed by the sudden and unexpected end to the inflation.

More importantly, a gradual reduction in the rate of inflation is bound to be obscured from time to time by incidental increases and decreases in costs due to changes in circumstances. These would hide the effect of the TIP or WIPP only temporarily, but could easily lead to the criticism that the anti-infiation plan is not working and the program would be dismantled before it had finished the job.

(4) There can be no real distinction between incentives to employers to increase their resistance to wage increases and incentives to workers to reduce their pressure for wage increases. In either case the incentive is the same tax on the same transaction. The remaining issue in all the TIPs is who should pay the tax and who should receive the "grant." This is the source of the litigation nightmare. WIPP solves this problem by its allocation of the property rights. The "tax" is paid by those who buy the permits, and the "revenue" is received by the sellers. A clear title to the property rights eliminates this litigation.

(5) Cutting excise taxes, or any other taxes that enter into cost, would reduce the costs and the price level, and so would reductions of monopolistic restrictions or of restrictions on imports. Such measures do increase economic efficiency, but they do not touch the core of our inflationary process. They lower the level of prices, but only once. They do nothing to prevent the exponential inflationary trend from continuing to rise and soon more than make up for the one-time decline in prices. Such windfalls could affect the inflationary trend only if there were a serendipitous succession of them that would flatten out the actual average price movement for a period long enough to establish expectations of further stability. Although such expectations would have to be based on unwarranted 
anticipation of continuing windfalls, they could establish a self-fulfilling expectation of stability-a zero rate of seli-fulfilling expectational inflation-but such a happy concatenation of windfalls is not likely to occur.

(6) If an efficient TIP were developed-one with the same incentives (tax or grant deduction) to hold down wage increases at all levels, the basic grant (before the deductions) would have to be equal to the sum of the taxes and the deductions, so that the remaining part of the grant would just counterbalance the deflationary effect of the taxes. If the grant were given only to workers who received wage increases less than the norm, we would have a problem (as seems to be implied in Seidman's approach-to induce workers to moderate their wage demands in order to reduce the penalty, the deductions from the grants). The amount of the grants would have to be twice that of the total deductions. Some way would have to be found to prevent workers from doing anything at all to qualify for some of the grant or to prevent themselves from being disqualified. Otherwise, the grant would no longer be "lump sum," that is, independent of the wage increase.

(7) It would not be possible for the government to compete with private industry for permits to raise the wages of their employees. The decision between public and private economic activity is a political one and cannot be left to the free market. However, the same principles are valid within the government sector. There would therefore have to be a separate set of government wage increase permits that operates within the government budget. This would check the inflation of government wages while permitting the different departments to compete with one another for employees. It would also yield the same demonstration that wage increases by any government component would have to come at the expense of wages in the other departments from which the government wage increase permits must come.

To have the same permits for government and for private industry would impose great pressure on the government to expand the budget in response to an increased price of permits and would result in a shift from private industry with its limited budgets to the government with its elastic budget.

(8) WIPP does not induce any shift from employing high-paid labor to low-paid labor. I would not consider it a disadvantage if it did. As long as there is greater unemployment among low-wage workers, such a shift would be socially most desirable (although full employment is much 
better). With full employment the effect would be to reduce income inequalities; this, too, is socially desirable. It is not even certain that efficiency would be sacrificed to equity in this case. Higher earnings are largely not rewards for investment in training but the result of discriminatory opportunities from one's parents in education, money, connections, and good advice; or just plain luck.

Nevertheless, the complaint is not valid, and any of the benefits mentioned above should be pursued directly. WIPP does not cause such a shift because the permits are proportional to the wages, and the charges for wage increases are proportional to the wage increases. Relative costs are unaffected.

The complaint does hold for TIPs with upper or lower limits to the range of wage increase subject to the incentives or for TIPs with different rates of incentive tax at different levels of the firm's average wage.

(9) WIPP will not add to average cost to be passed on in additional price increases because the increase in cost to those who buy permits is exactly balanced by the decrease in cost to those who sell the permits; and in any balanced TIP the taxes that add to cost are kept equal to the offsetting grants that do the opposite. There remain only the effects of the reduction in the wage increases.

(10) A frequent objection is that the price of the permits would be too high for practical purposes. It is impossible for the price to be "too high." It cannot be higher than what the buyers are willing to pay!

Astronomical figures are obtained by counting the capital value of a permanent permit (which would allow wage increases to be paid forever) with the assumption that the inflationary pressure would last forever. But the WIPP permits are annual permits.

The permits could also be used to work in the opposite direction if a self-fulfilling expectation of falling average prices and wages, such as that of the 1930s, should ever arise again. An incentive against decreases in wages would then be needed, together with a requirement that permits raise the wage bill less than the 3 percent required for price stability (and a requirement for still more such permits for actually lowering the wage bill). This would have served to cure the self-fulfilling deflation of the 1930s; it could be what was sought in the pre-New Deal attempts of the National Industrial Recovery Act to raise prices, such as "Blue Eagle" appeals to patriotism and ideology or the 1934 increase in the price of gold. 
(11) Some concern has been expressed that there would be speculation and hoarding of permits. I can see no harm in speculation, but if it is desirable to prevent fluctuations in the price of the permits to make it easier for firms to plan, it would be possible for the government to engage in "counterspeculation"- - that is, buying and selling permits and pegging their price. The problems here are identical with those of fixing the rate of foreign exchange. (The concept of counterspeculation is developed in my books, The Economics of Control, 1944, and Flation, 1972.) In this case, as in the case of foreign exchanges, $I$ think the argument for a freemarket price is the most convincing one.

There is no "hoarding" problem. Any permits purchased for speculative purposes would be loaned out and would still perform their function. The owner of a permit can gain nothing by holding it unused.

(12) There is also the issue of compliance. WIPP requires monitoring to ensure that there is no cheating. This has been considered equivalent to the problem of monitoring compliance with the wage and price regulations of the controls period. However, in that case innumerable prices of different products as well as different wages had to be checked for compliance to see if they were in accordance with the guidelines, and all the problems of checking the quality of products and grades of labor were encountered. None of these applies to WIPP. There is only the problem of ensuring that people do not claim to possess permits that they do not have or provide false wage statements. These situations involve only the detection of fraud. They do not seem to be different in kind or volume from those that are currently being handled by the Internal Revenue Service in connection with auditing the income tax.

(13) WIPP does not require calculations of average wage, classified or unclassified.

(14) It is certain that WIPP and most forms of TIP would be denounced as antilabor because they regulate wages and not prices. Workers might fear that holding down wages would not result in a corresponding constraint on prices so that real wages could fall. The government could alleviate such fears by a guarantee to compensate all employees for the average decline in real wages or for wages failing to increase by a considerable amount. There would be little risk in this for the government. If, in fact, real wages increased by less than the increase in productivity, enormous profits would have been made on which the government could collect high taxes. 
It is most inadvisable for the government to attempt to win the support of the workers by giving them an initial tax rebate equal to the wage increase that is prevented by TIP or WIPP. It would give the workers a large increase in real income. The pay raise, based on anticipated inflation, would be used to buy goods at the disinflated prices. It would preempt a major part of the benefits from the possible increase in output generated by the success in combating the depression. Although the pay raise would be worth paying for the sake of obtaining future benefits, there is the danger that it would establish a precedent for workers to expect more than the economy could provide for them in wages; moreover, it could develop into a permanent and economically devastating subsidy to wages that would entail heavy taxation and drastic reductions in government services to prevent demand inflation.

(15) It is frequently implied and occasionally even stated explicitly that workers must want the inflation or else they would not insist on pay increases that are responsible for it. But even if it were conceded that all workers were good economists and understood this, it does not follow that they want the result. No workers decide to attempt to raise wages in general. They decide only to push for the increase in the wages of their particular group. The purpose of TIP and, indeed, the primary purpose of WIPP is to internalize the externality by placing into the particular pay envelope the effects of the wage increase decision on the economy as a whole. To say that workers make individual demands because they want the collective result is similar to saying that, in the case of a fire, people who rush to the exit, knowing that if they individually rush to the exits those exits will block and they will collectively perish, must desire that result! 